\title{
HIGHER RADIAL MODES OF AZIMUTHAL SURFACE WAVES ABOVE THE UPPER-HYBRID FREQUENCY IN CYLINDRICAL WAVEGUIDES PARTIALLY FILLED BY PLASMA
}

\author{
I. Girka, V. Kondratenko \\ V.N. Karazin Kharkiv National University, Kharkiv, Ukraine \\ E-mail: igorgirka@karazin.ua
}

\begin{abstract}
Azimuthal surface waves (ASWs) are known to be eigen waves of cylindrical metal waveguides partially filled by magnetoactive plasma. Zeroth radial modes were under study earlier. Their dispersion properties are known to be significantly influenced by the plasma column properties: its particle density, external axial static magnetic field, geometric dimensions, - rather than properties of the dielectric layer which separates the plasma column from the metal wall. Application of higher order ASWs in the low-frequency range was shown earlier to make it possible to get advantage of exciting ASWs with higher frequency than in the case of zeroth order ASWs without no change in the waveguide design. The present study generalises those investigation for the case of the waves above the upperhybrid frequency.
\end{abstract}

PACS: 52.25.Xz, 52.35.Lv

\section{INTRODUCTION}

Surface type electromagnetic waves in plasmas are known to have some advantages as compared to volume waves in technological applications [1-3]. Their excitation does not need to spend energy for creating the wave structure in the plasma core as it takes place in the case of volume waves. Since ASWs propagate with zero axial wavenumber, $k_{z}=0$, plasma electronic devices ion their base can be designed with smaller axial dimensions [3].

Dispersion properties of zeroth radial modes of extraordinarily polarized ASWs (XASWs) in cylindrical metal waveguides partially filled by plasma column in external axial static magnetic field, $\vec{B}_{0} \| \vec{z}$, were studied in details in $[3,4]$. XASWs propagate with the wave field components $E_{r}, E_{\varphi}$, and $H_{z}$ independently from ordinarily polarized ASWs (OASWs) which propagate with the wave field components $H_{r}, H_{\varphi}$, and $E_{z}$. The spatial-temporal dependence of the wave fields has the following form, for example, for the axial wave magnetic field:

$$
H_{z}(\vec{r})=H_{z}(r) \exp [i(m \varphi-\omega t)] .
$$

In (1), $m$ is azimuthal wavenumber, $\varphi$ is azimuthal angle and $r$ is radial coordinate in cylindrical coordinates, $\omega$ is wave angular frequency, and $t$ is a time.

The results of $[3,4]$ were generalized in $[5]$ to the case of higher radial modes in low-frequency (LF) range

$$
\omega_{L H}<\omega<\left|\omega_{e}\right|, \quad\left|\omega_{e}\right|<\omega<\omega_{1} .
$$

In (2), $\omega_{1}=-\left|\omega_{e}\right| / 2+\sqrt{\Omega_{e}^{2}+\omega_{e}^{2} / 4}$ is the cut-off frequencies for bulk modes, and $\omega_{L H}$ is the lower hybrid frequency, $\omega_{e}$ and $\Omega_{e}$ are electron cyclotron and plasma frequencies, respectively. Plasma particle density is assumed to be sufficiently large and external axial static magnetic field is assumed to be sufficiently small in the present paper, so that $\Omega_{e}>\left|\omega_{e}\right|$.

They use to study the dispersion properties as a dependence of an eigen frequency as a function of a wavevector. In the case of ASWs, the ratio $m / a$ could play the role of characteristic azimuthal wavenumber with $a$ being the plasma column radius. In the most of previous papers devoted to ASWs, the frequency was studied in dependence on dimensionless effective wavenumber $k_{e f}=|m| \delta / a$ with $\delta=c / \Omega_{e}$ being the skindeplth. XASW eigen frequency of the zeroth radial mode is known not to reach the upper limit of the LF frequency range (2) regardless of the $k_{\text {ef }}$ magnitude. They are higher radial modes of XASWs whose frequencies overlap entire range (2) [5]. This advantage of higher radial modes initiated investigation of their application for XASW excitation by electron beam gyrating around the plasma column along large Larmor orbits [6]. The first radial mode of LF XASWs was shown to be appropriate to be used for excitation for the following reasons. Its frequency could be sufficiently higher than that of the zeroth radial mode ceretis paribus while its growth rate could be a little bit smaller than that of the zeroth radial mode. However, the growth rate of the second radial mode appears to be much smaller than that of the zeroth radial mode which makes meaningless the application of the second radial mode.

Explicit expressions for the limits of the range (2) were obtained in [4] from the condition of surface nature of XASWs in the plasma: $k_{\perp}^{2}>0$. "Surface nature" means that amplitudes of the XASW fields decrease with going away from the plasma column boundary into the plasma core. For example, the amplitude of axial wave magnetic field behaves as modified Bessel function $\mathrm{I}_{m}(\xi)$ :

$$
H_{z}(r)=A I_{m}\left(k_{\perp} r\right) \text {. }
$$

In (3), $k_{\perp}{ }^{2}=(\omega / c)^{2} \varepsilon_{1}\left(\mu^{2}-1\right)$ with $\mu=\varepsilon_{2} / \varepsilon_{1}, \varepsilon_{1,2}$ are the components of cold collisionless plasma dielectric permittivity tensor $\varepsilon_{i j}$ : $\varepsilon_{1} \equiv \varepsilon_{11}$, and $\varepsilon_{2} \equiv-i \varepsilon_{12}$ :

$$
\varepsilon_{1}=1-\sum_{\alpha} \frac{\Omega_{\alpha}^{2}}{\omega^{2}-\omega_{\alpha}^{2}}, \quad \varepsilon_{2}=-\sum_{\alpha} \frac{\Omega_{\alpha}^{2} \omega_{\alpha}}{\omega\left(\omega^{2}-\omega_{\alpha}^{2}\right)} .
$$

The condition $k_{\perp}^{2}>0$ is valid also in the frequency range above the upper-hybrid frequency $\omega_{U H}$ :

$$
\omega_{U H}<\omega<\omega_{2}
$$


where $\omega_{2}=\left|\omega_{e}\right| / 2+\sqrt{\Omega_{e}^{2}+\omega_{e}^{2} / 4}$ is the cut-off frequency for bulk modes. The objective of the present paper is to study the dispersion properties of XASW higher radial modes just in this frequency range.

In general, expression for the amplitude of the wave axial magnetic field as a solution of Maxwell's equations contains two constants of integration. The Eq. (3) contains only one constant since the expression accounts the boundary condition at the axis of the waveguide. The wave fields should be of finite magnitude there.

\section{STATEMENT OF THE PROBLEM}

The following plasma-dielectric-metal cylindrical structure is under the consideration. Cold plasma column with a circular cross-section of radius $a$ is separated from the loss-free metal wall of radius $b$ by the dielectric layer with dielectric constant $\varepsilon_{d}$. The structure is placed into external axial static magnetic field $\vec{B}_{0} \| \vec{z}$ (Fig. 1).

Within the dielectric layer the amplitude of the wave axial magnetic field is described in terms of the Bessel functions of the first, $J_{m}(x)$, and second, $N_{m}(x)$, kinds [6]:

$$
H_{z}(r)=B\left[J_{m}(\kappa r) N_{m}^{\prime}(\kappa b)-N_{m}(\kappa r) J_{m}^{\prime}(\kappa b)\right] .
$$

In (6), the radial wave vector is $\kappa=\omega \sqrt{\varepsilon_{d}} / c$. The Eq.

(6) contains only one constant of integration to satisfy the boundary condition at the ideal metal interface, where wave tangential (azimuthal) electric field should be equal to zero.

Application of the boundary conditions at the plasmadielectric interface $\left(H_{z}(r)\right.$ and $E_{\varphi}(r)$ should be continuous at $r=a)$ results in the dispersion relation [3, 4]:

$$
\begin{aligned}
& \frac{\kappa}{k_{\perp}} \frac{J_{m}^{\prime}(\kappa a) N_{m}^{\prime}(\kappa b)-J_{m}^{\prime}(\kappa b) N_{m}^{\prime}(\kappa a)}{J_{m}^{\prime}(\kappa b) N_{m}(\kappa a)-J_{m}(\kappa a) N_{m}^{\prime}(\kappa b)}= \\
& =\frac{I_{m}^{\prime}\left(k_{\perp} a\right)}{I_{m}\left(k_{\perp} a\right)}+\frac{\mu m}{k_{\perp} a} .
\end{aligned}
$$

In (7), the primes denote derivatives with respect to the argument.

\section{ASYMPTOTIC SOLUTIONS OF THE DISPERSION RELATION}

The asymptotic solution of the dispersion relation (7) in the case of LF XASWs and small depth of the wave penetration into the plasma, $k_{\perp} a>>1$ (that is $k_{e f}<<1$ ), was given in [5]:

$$
\omega \approx \frac{\pi l c}{\sqrt{\varepsilon_{d}}(b-a)}\left[1-\frac{m \mu c^{2}}{\Omega_{e}^{2} a(b-a)}\right] .
$$

In (8), $l$ is the wave radial mode number.

Nearby the upper limit of the LF frequency range (2), the depth of the wave penetration into the plasma becomes large, $k_{\perp} a<<1$, and eigen frequency of LF XASWs with positive azimuthal wavenumber writes as:

$$
\omega \approx \frac{c}{\sqrt{\varepsilon_{d}}(b-a)}\left[\pi(l-0.5)+\frac{a \Omega_{e}}{2 c|m| \sqrt{\varepsilon_{d}}}\right] .
$$

In the case of $m<0$, asymptotic expression for LF XASWs looks like Eq. (9) with the different second term in square brackets:

$$
\omega \approx \frac{c}{\sqrt{\varepsilon_{d}}(b-a)}\left[\pi(l-0.5)+\frac{2(|m|+1)}{\kappa a}\right] .
$$

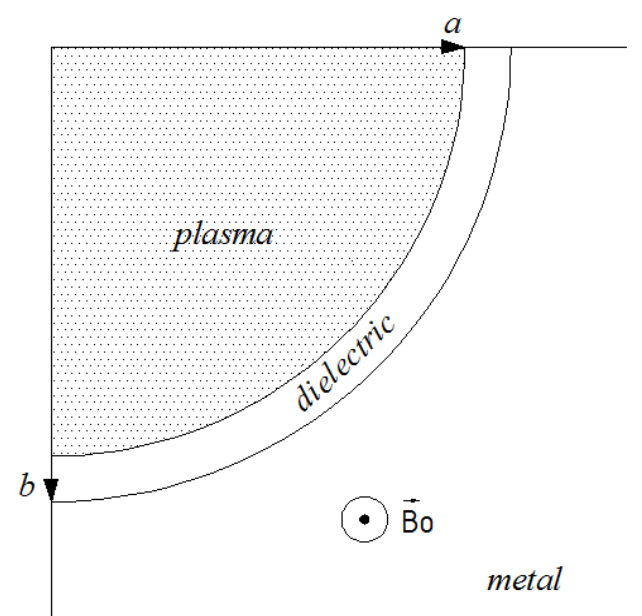

Fig. 1. Geometry of the problem

Nearby the upper limit of the HF frequency range (5), one can apply the Eq. (9) as asymptotic expression for the eigen frequency of HF XASWs which propagate with negative azimuthal wavenumbers, and Eq. (10) in the case of HF XASWs which propagate with positive $m$ with replacing $l$ by $(l+1)$.

Solid curves in Fig. 2 show the dependence of XASW eigen frequency normalized by the electron cyclotron frequency as a function of effective wavenumber. Numerals near the curves mark the radial mode number $l$. Dash-dotted lines correspond to the limits of the frequency ranges (2) and (5). Dashed curve shows the asymptote (8). It exceeds the respective curve for $l=2$ by less than $16 \%$, the accuracy being better for smaller $k_{e f}$. Although the asymptote (10) exceeds the magnitude of HF XASW with $l=1$ by less than $18 \%$, its curve is not shown in Fig. 2, since it would lie above the range (5).

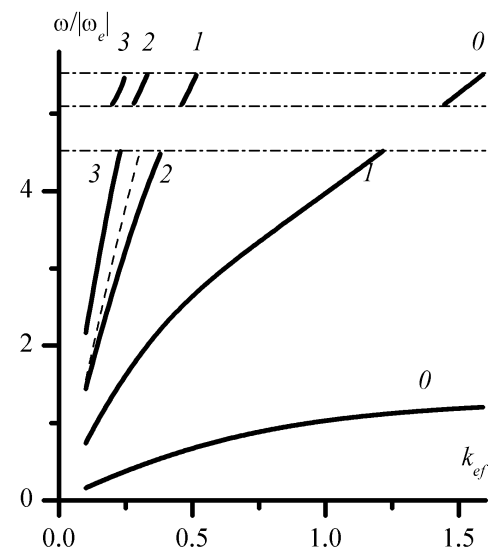

Fig. 2. XASW eigen frequency vs $k_{\text {ef }}$ $Z \equiv \Omega_{e} \bigwedge \omega_{e} \mid=5, b / a=2, \varepsilon_{d}=4, m=-1$ 
Those sections of the dispersion curves of $\mathrm{HF}$ XASWs, which are described by the Eqs. (3) and (4) and correspond to the frequencies near the upper limit of the range, are situated closely to each other. The curve with the radial wavenumber $(l+1)$ is situated on the left hand of that with $l$. The higher is the radial wavenumber $l$, the less is distance $\Delta k_{e f}(l+1, l)$ between the two curves which correspond to two neighboring radial wavenumbers $(l+1)$ and $l, \Delta k_{e f}(l+1, l) \propto l^{-2}$. Increase of the radial wavenumber $l$ is accompanied by the approach of the dispersion curve to the vertical disposition. The angle between the sections under the consideration and a vertical line is inversely proportional to $l$.

\section{RESULTS OF NUMERICAL ANALYSIS}

In Figs. 3-7, the results of numerical analysis of the dispersion relation are presented in the form of dependencies of XASW eigen frequency $\omega$ on effective wavenumber $k_{e f}$. Choice of $k_{e f}$ as an ordinate makes it possible to study the $\omega$ as a function of the plasma column radius and its particle density. Eigen frequency is normalized by electron cyclotron frequency, except of the Fig. 5, wherein the influence of axial static magnetic field $B_{0}$ is studied, and $\omega$ is normalized by the Langmuir frequency $\Omega_{e}$.

Application of $\vec{B}_{0}$ is known to remove the spectrum degeneracy in the respect of azimuthal wavenumber sign. Analytical study predicts $\omega(+|m|)>\omega(-|m|)$ for both HF and LF ranges (note, $\mu<0$ in LF range (2)), which is confirmed by the calculations in Fig. 3. The difference between the curves related to LF XASWs with $m= \pm 1$ is invisible already for $l=3$.

Decreasing of LF XASW eigen frequency with increasing of azimuthal wavenumber absolute value was shown for higher radial modes in [5].

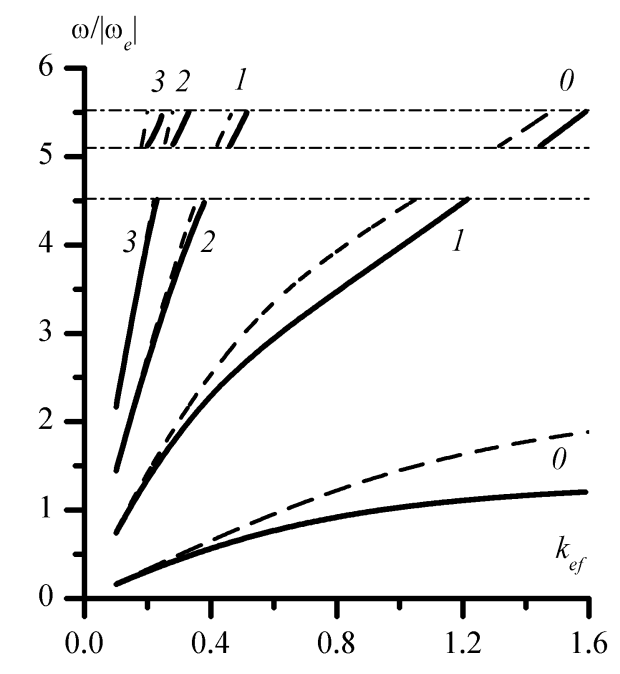

Fig. 3. XASW eigen frequency vs $k_{\text {ef }}$ $Z=5, b / a=2, \varepsilon_{d}=4$,

$m=-1$ (solid curves), $m=+1$ (dashed curves)

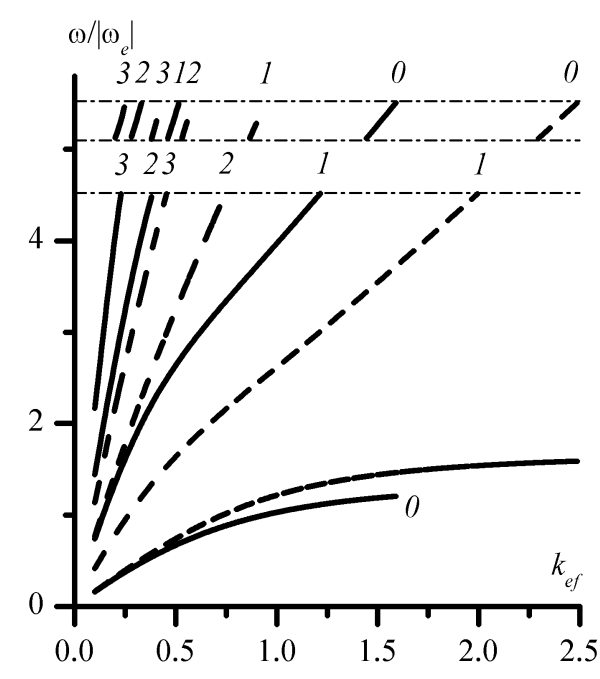

Fig. 4. XASW eigen frequency vs $k_{\text {ef }}$. $Z=5, b / a=2, \varepsilon_{d}=4, m=-1$ (solid curves), and $m=-2$ (dashed curves)

This behavior is in qualitative agreement with the asympto-te (8). Analogous qualitative dependence of HF XASW frequency on the $|m|$ is predicted by the asymptote (9).

Although axial static magnetic field is not present in asymptotic expressions (9) and (10), it is a necessary element of plasma electronic devices based on electron beams rotating in $\vec{B}_{0}$ around the plasma column. Significant increase of $B_{0}$ in Fig. 5 causes weak increase of the HF range and weak decrease (increase) of $\omega$ for fixed $k_{e f}$ for XASWs with negative (positive) $m$.

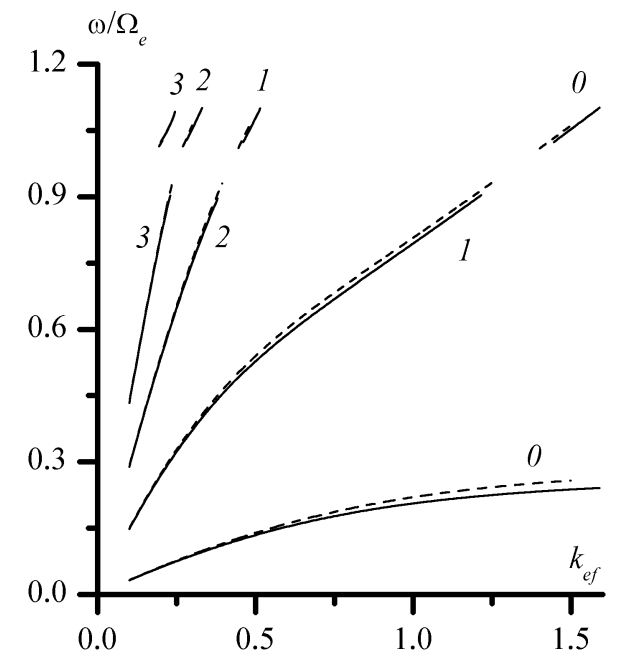

Fig. 5. XASW eigen frequency vs $k_{\text {ef }}$ $Z=5$ (solid curves), $Z=8$ (dashed curves), $b / a=2, \varepsilon_{d}=4, m=-1$

\section{CONCLUSIONS}

A comprehensive analysis of the dispersion properties of the higher radial modes of HF XASWs is presented. The dependence of HF XASW eigen frequencies on the parameters of the plasma waveguide (radius of the plasma column and the metal wall, plasma particle density, azimuthal wavenumber and 
dielectric constant) is studied for the case of higher radial modes. HF XASW eigen frequency is shown to increase with decreasing dielectric layer width $(b-a)$, absolute value of azimuthal mode number $|\mathrm{m}|$, dielectric constant $\varepsilon_{\mathrm{d}}$, and especially with increasing the radial mode number $l$. An increase in the constant axial static magnetic field $B_{0}$ causes a weak decrease in the eigen frequency of the higher radial HF XASW modes for the given magnitude of effective wavenumber. The dispersion properties of the higher radial HF XASW modes are compared with the properties of the zero radial HF XASW mode. Eigen frequencies of HF XASWs with positive azimuthal wavenumbers are shown to be higher than those of XASws with negative $m$.

Increase in the radial mode number $l$ (decrease in the width of the dielectric and its dielectric constant) causes shift the HF XASW dispersion curve towards smaller magnitudes of the effective wavenumber, which means larger magnitudes of the plasma column radius $a$ and particle density $n_{e}$. Application of higher radial modes of HF XASWs does not give any gain in the form of increasing the frequency compared to the zeroth mode, as it is in the case in the LF range, but expands the range of parameters of the plasma waveguide for which they can be excited towards larger values of $n_{e}$ and/or $a$.

The results obtained in the present paper can be of interest for plasma electronics and medical physics [8].

\section{REFERENCES}

1. M. Moisan, H. Nowakowska. Contribution of surface-wave (SW) sustained plasma columns to the modeling of RF and microwave discharges with new insight into some of their features. A survey of other types of SW discharges // Plasma Sources Science and Technology. 2018, v. 27, № 7, p. 073001.
2. N.A. Azarenkov,
K. Ostrikov.
Surface

magnetoplasma waves at the interface between a plasma-like medium and a metal in a Voigt geometry // Physics Reports. 1999, v. 308, p. 333-428.

3. V. Girka, I. Girka, M. Thumm. Surface flute waves in plasmas. Theory and applications. Springer-Verlag, Cham, Heidelberg, New York, Dordrecht, London, 2014.

4. V.A. Girka, I.A. Girka, A.N. Kondratenko, V.I. Tkachenko. Azimuthal surface waves of magnetoactive plasma wavequides // Soviet Journal of Communications Technology and Electronics. 1988, v. 33, № 8, p. 37-41.

5. I.O. Girka, V.M. Kondratenko, M. Thumm. Higher radial modes of azimuthal surface waves in magnetoactive cylindrical plasma waveguides // Journal of Plasma Physics. 2018, v. 84, Issue 6, p. 905840603.

6. I.O. Girka, I.V. Pavlenko, M. Thumm. Excitation of higher radial modes of azimuthal surface waves in the electron cyclotron frequency range by rotating relativistic flow of electrons in cylindrical wave-guides partially filled by plasmas // Physics of Plasmas. 2018, v. 25, p. 052109.

7. M. Abramowitz, I. Stegun. Handbook of mathematical functions with formulas, graphs, and mathematical tables. Washington: "National Bureau of Standards", 1972.

8. S. Baieva, J.A. Ihalainen, J.J. Toppari. Strong coupling between surface plasmon polaritons and $\beta$ carotene in nanolayered system // Journal of Chemical Physics. 2013, v. 138, p. 044707.

Article received 28.09.2020

\section{ВЫСШИЕ РАДИАЛЬНЫЕ МОДЫ АЗИМУТАЛЬНЫХ ПОВЕРХНОСТНЫХ ВОЛН ВЫШЕ ВЕРХНЕЙ ГИБРИДНОЙ ЧАСТОТЫ В ЦИЛИНДРИЧЕСКИХ ВОЛНОВОДАХ, ЧАСТИЧНО ЗАПОЛНЕННЫХ ПЛАЗМОЙ}

\section{И. Гирка, В. Кондратенко}

Известно, что азимутальные поверхностные волны (АПВ) являются собственными волнами цилиндрических металлических волноводов, частично заполненных магнитоактивной плазмой. Нулевые радиальные моды АПВ изучены ранее. Известно, что на их дисперсионные свойства заметнее влияют параметры плазменного столба: плотность его частиц, внешнее аксиальное постоянное магнитное поле, геометрические размеры, - чем свойства диэлектрического слоя, который отделяет плазменный столб от металлической стенки. Ранее было показано, что применение высших радиальных мод АПВ в низкочастотном диапазоне позволяет достичь преимущества при возбуждении АПВ в виде более высокой частоты, чем в случае нулевой радиальной моды АПВ, без каких-либо изменений в параметрах волновода. Эта работа обобщает проведенные ранее исследования на случай волн выше верхней гибридной частоты.

\section{ВИЩІ РАДІАЛЬНІ МОДИ АЗИМУТАЛЬНИХ ПОВЕРХНЕВИХ ХВИЛЬ ВИЩЕ ВЕРХНЬОЇ ГІБРИДНОЇ ЧАСТОТИ В ЦИЛІНДРИЧНИХ ХВИЛЕВОДАХ, ЯКІ ЧАСТКОВО ЗАПОВНЕНІ ПЛАЗМОЮ}

\section{І. Гірка, В. Кондратенко}

Відомо, що азимутальні поверхневі хвилі (АПХ) $є$ власними хвилями циліндричних металевих хвилеводів, які частково заповнені магнітоактивною плазмою. Нульові радіальні моди АПХ вивчені раніше. Відомо, що на їхні дисперсійні властивості більш значною мірою впливають параметри плазмового стовпа: густина його частинок, зовнішне аксіальне стале магнітне поле, геометричні розміри, - ніж властивості діелектричного шару, який відокремлює плазмовий стовп від металевої стінки. Раніше було показано, що застосування вищих радіальних мод АПХ в низькочастотному діапазоні дає можливість досягти перевагу при збудженні АПХ у вигляді більш високої частоти, ніж у випадку нульової радіальної моди АПХ, без жодних змін у параметрах хвилеводу. Ця робота узагальнює проведені раніше дослідження на випадок хвиль вище верхньої гібридної частоти. 